\title{
Main pathogenetic chains
}

\section{Editorial}

Oxidant molecules highly reactive oxygen may be generated at the influx of oxygen into body cells. Lipids form the cell membrane and lipids may be oxidized. The oxidation is accelerated if membranes are largely made by unsaturated fatty acids. Blood red cells may shorten survival for unsaturated fatty acids. The oxidation contributes to red cell senescence which is contrasted by Vitamins E, C, A. Vegetables form an actual defense. Overall oxidation of body cells may be a factor of senescence. Leucocytes put out active oxygen to kill bacteria and demolish endotoxin: Inflammatory reactions ought to be reduced to avoid or impair active oxygen use. Forty grams of leukocytes are produced every day in healthy conditions. This amount becomes 200 grams during fever. Prevention of this production includes limitation of Inflammatory reactions.

Lack of minerals $(\mathrm{Ca}, \mathrm{Zn}, \mathrm{Fe}, \mathrm{Cu})$ reduces cell lifespan. As an assumption, not-starchy vegetables contain more or much more minerals and vitamins than energy dense vegetables. Energy intake is the limiting factor for all food. Yet we do not know how these deficiencies impair and damage metabolism and cells. Poor vegetable intake may occasionally produce deficiencies and even diseases. This suggests improving intake of these minerals. Lack of these minerals shortens the cell lifespan poorly. A bacterial film over the cell lining may be more effective: the lifespan halves.

Cholesterol is largely blamed for vascular damage. There is no explanation for the damage mechanism. Statins are able to decrease plasma value but the association with the vascular risk decrease is poor. Moreover, cholesterol is useful to promptly give cell membrane when cell proliferation and membrane turnover increases for inflammation. Cholesterol might be a sign of this situation and statins might be poorly useful although capable of cholesterol decrease.

Cell lifespan has a genetic regulation. Genetic and inborn errors limit organ and cell functions. Insulin resistance, bacterial overgrowth on intestinal mucosa, overall increase in immune stimulation damage all body and may determinate local, prolonged cell proliferation with an increased risk of a local malignant deviation. The malignant growth requires an efficient immune system to stop rapid evolution.

Traumas seem to develop (and start repair) without involving the immune system. This is true at the beginning. The late repair phase instead may receive inflammatory stimuli from overall inflammation thus largely involving immune defenses.

Viral and bacterial offenders evoke an inflammatory reaction that leaves frequent sequels of overall inflammation.

Anxiety may be totally born in mind although often a low grade inflammation may contribute to the intensity and prolongation of the anxious state. An inflammatory component can often not be excluded. In a search for continuous healthy state, inflammatory events ought to be rare to leave as few inflammatory sequels as possible.

The immune system participates to all ill events.
Volume 8 Issue I - 2018

\author{
Mario Ciampolini \\ Preventive Gastroenterology Unit, Department of Paediatrics, \\ Universita di Firenze, Italy
}

Correspondence: Mario Ciampolini, Preventive

Gastroenterology Unit, Department of Paediatrics, Università di

Firenze, Italy, Email mlciampolini@fastwebnet.it

Received: January 06, 2018 | Published: January 09, 2018

This list of trivial events is similar to a day working in primary care. We presented it to let understand that illness is often or always an involvement of the immune system. Assistance ought to invest on early and complete fighting against inflammatory factors. Suppression of these factors, most diseases will ameliorate.

This list let me suggest to think that half or more immune cells are located in small intestinal mucosa. I took medical decisions on this ground. First of all energy balance, because the positivity of balance is correlated with a decrease in intestinal peristalsis, in small intestine absorption, in bacteria overgrowth on small intestine mucosa and excess response by immune cells locally and overall inflammation for antigen perfusion in the body, i.e., a poor life for functional disorders (like backpain) and a risky life for vascular diseases.

\section{To be or not to be}

Last Summer I broke my left femur. Now, I freely walk in my home. BMI of 20. At $85 \mathrm{I}$ am eating 600 to $900 \mathrm{kcal}$ per day, fruit at breakfast including one banana and/or boiled fruit including prunes. A lunch with cooked not starchy vegetables, $50-100$ gram cereals or three times this weight of potato, 150 grams fish or chicken. No dinner, often fruit, at best one big orange, sometimes cooked fruit. Initial problems of incontinence. I go to bed with edematous ankles and cyanotic lips, sitting pulse rate $64 / \mathrm{min}$, atrial fibrillation. After ten hours of slip, edema subsides and lips are less cyanotic, sometimes lips are red. I have one - two additional sleeping hours in the afternoon. Soon after breakfast, I walk about $4 \mathrm{~km}$ with my wife; before the femur breaking I walked $8 \mathrm{~km}$. On the basis of going up on home stairs (90 steps), my heart flux halved 6 years ago after the arrival of fibrillation. Five hours per day at the computer. Following the current energy intake rules, I might go on for one - three months. My wife and sons prohibited me any participation to international conferences, although I always had exceptional successes. Is this life acceptable? To dye means a stop in helping others, it means also no love for anybody. I am faithful about my findings. Do persist in civil relations and in searching for good in the remainng tract of life. Thus I decided to live other ten years. 